\title{
О.А. ГУБАНОВ
}

\section{СИМУЛЯКРЫ В ДИГИТАЛЬНОМ БЫТИИ МУЗЫКИ. СЕМАНТИКО-СИНТАКСИЧЕСКИЙ УРОВЕНЬ СИМУЛЯКРИЗАЦИИ ДИГИТАЛЬНОЙ МУЗЫКИ}

Представлены результаты художественно-эстетического анализа дигитально-модифицированной музыки. По мнению автора, симулякризация является одним из базовых свойств цифрового бытия музыки. Выделены уровни симулякризации дигитальной музыки - семантико-синтаксический (сочинение и исполнение музыки, запись фонограммы) и прагматический (воспроизведение, интерактивное восприятие).

Ключевые слова: музыка, дигитальность, виртуальность, симулякр, запись, обработка звука, интерактивность, ультрамузыка.

C 80-х годов XX века обретает популярность новый способ фиксации аудиоинформации - цифровой (или дигитальный). По сравнению с аналогом, он технически более совершенный и достоверный. Возникает целый дигитальный универсум - беспрецедентная в истории человечества виртуальная звуковая среда, которая предлагает новые способы сочинения, исполнения и даже восприятия музыки. Несмотря на доступность и технологическую точность цифровой записи, субъективно она зачастую проигрывает аналогу. Если профессиональная аналоговая запись отличается теплотой, благородством и богатством гармоник (а зачастую и некой эстетической дистанцией, отдаляющей ее от слушателя), то цифровая запись всегда более «холодная» и проигрывает аналогу в передаче душевных чувств исполнителей, хотя технически более достоверна. Цифровая запись стремится компенсировать собственную недостоверность последующей обработкой звука, который все же не становится подобным акустическому прототипу, но «обманывает» слух ложным совершенством (совершенством динамических, частотных и пространственных характеристик), техническим совершенством, делающим звук «лучше» первоисточника.

В дигитальной записи с помощью аналого-цифрового преобразователя звуковые колебания превращаются в последовательность импульсов, представляемых на компьютере в виде чисел, и могут быть сохранены на физическом носителе для последующего воспроизведения записанного сигнала. При помощи специальных устройств и программного обеспечения цифровые аудиоданные могут быть подвергнуты любой коррекции (добавление сэмплов, изменение тембра, скорости звука, вырезание и склеивание аудиофрагментов и т. д.). Как правило, для наиболее совершенного звучания применяется комплекс технико-эстетических процедур. Аудиотрек подвергается очистке от шумов, неизбежных при аналого-цифровом преобразовании, динамической и частотной редактуре, добавлению пространственно-стереофонической информации. В дигитальности появляется возможность генерировать собственные звуки, не имеющие никаких реальных акустических прототипов. Для воспроизведения цифрового звука применяется специальное оборудование: музыкальные центры, цифровые плееры, компьютеры со звуковой картой и установленным программным обеспечением.

Сегодня цифровые аудиотехнологии используются массово. Не только в академическом авангарде, но и в самой широкой массовой культуре. В ней дигитальность, благодаря огромным новым возможностям, стала единственным стандартом. Выход аудиотехнологий из пространства элитарных экспериментов в массовое культурное распространение невероятно обострил тему аудиодигитальности, поставил огромное количество новых проблем, которые в самом общем виде рассматриваются в данной статье.

\section{Синтезированный, программируемый звук как симулякр}

С появлением дигитальности возник вопрос о природе цифрового звука, релевантности системы «0» и «1» для запечатления музыки и чисто технически - как акустической волны, и метафизически - насколько пригодны нули и единицы для того, чтобы фиксировать ее духовную сущность. Нередко приходится слышать от музыкантовакадемистов, что в цифровом звучании классики пропадает что-то самое главное. Специфика компьютерной обработки и передачи информации, базирующаяся на последовательности двух цифр («0» «1»), создает идеальную среду для бытования симулякров.

На самом деле основы симулякризации чисто технические. Дело в том, что любая цифровая запись в основе своей имеет бинарный код, имитирующий физические колебания реальных акустических источников или синтезирующий собственные звуки. Слушая дигитальный аудиопродукт, нужно помнить, что имеем дело с неким техническим симулякром - подобием живого источника звука или не имеющим никакого прототипа дигитальным 
объектом. Возможно также комбинирование этих типов в одном аудиосигнале. Бинарный способ записи никогда не сможет адекватно передать звучание живых инструментов, и всегда будет вносить значительные искажения. Он всегда снимает лишь часть звуковых волн, не улавливая всех отражений - полноты стереопанорамы.

Таким образом, звук отрывается от естественной акустической среды обитания и в общем-то теряет образ, сохраняя лишь подобие, то есть становится симулякром в самом классическом смысле. Симулякризация в дигитальном музыкальном пространстве хорошо прослеживается в сэмплировании звучания акустических инструментов. Виртуальные симулякры акустических инструментов бывают нескольких уровней: от симуляции достоверной копии (сэмплы Steinway, 50 гб) через деградирующие «копии» (виртуальный, встроенный в Sonar XI сэмплер рояля) к низшему уровню, где «идея» (саунд) акустического инструмента значительно искажена (GENERAL MIDI на встроенной звуковой карте). Дигитальное аудиопространство вбирает в свое поле имитацию реального бинарнооперациональным лишь как один из возможных уровней.

Компьютер не смог создать синтезированным способом идеальные симулякры акустического пространства. Однако при этом наметилась новая тенденция гиперсимуляции: создание антропо-кибернетического симулякра (сэмплирование живого «Steinway» и дальнейшее его преобразование).

Характерно, что, разорвав связь со своей естественной акустической, «природной» средой обитания, дигитально-модифицированная музыка была вынуждена разорвать заодно и с нотным письмом - еще одной своей традиционной, хотя и вовсе не исконной средой. Ведь именно появлению нот, нотной грамоты во многом обязано развитие музыкального искусства в последние несколько столетий. Наличие письма, нотного письма, способствовало формированию уникальной европейской музыкальной культуры. Со сменой стилей, эпох модифицируется и нотная запись. Легко уловить идентичность графики нотного письма и той музыкальной эпистемы, к которой она принадлежит. Так, со времен барокко и вплоть до авангардизма можно уловить все большую собранность, концентрированность нот, все большее количество специальных знаков, авторских ремарок и др.

При этом дигитальный период обозначил следующий шаг - полный отказ от нотной записи с любым количеством ремарок вообще, поскольку такая запись стала просто нерелевантной новому предмету. Теперь радикально сместилась роль средств выразительности и новые их преобразованные виды уже никак не зафиксировать «традиционным» письмом, оно переходит в электронно-цифровой вид, чем обусловлена прерогатива новой категории - саунда.

Современная цифровая музыка не может быть достоверно отражена в нотной записи, она распространяется в аудио- и MIDI-форматах ${ }^{1}$.

\footnotetext{
${ }^{1}$ MIDI - это цифровой способ обмена данными между электронными
} музыкальными устройствами. MIDI позволяет кодировать различные
Для создания симулякра живого исполнения MIDIдорожки намеренно «искривляются», так создается подобие живого исполнения или просто не квантизуются (т. е. не выравниваются идеально по длительностям). С целью оживления MIDI можно сделать в аудиотреке незначительные темповые сдвиги, создающие ощущение дыхания музыки. Есть возможность также «расстроить» некоторые инструменты (эта функция называется detune), чтобы привнести в музыку живую интонацию (естественно, в виде ее симулякра).

В некоторых сэмплерных библиотеках инструменты изначально немного расстроены. Однако вряд ли это спасает цифровой софт от «синтетической примеси» в звуке. Дигитальные сэмплерные библиотеки представляют собой коллекции записанных «живых» инструментов (всего их диапазона и всех видов артикуляций) и создание на их основе виртуальных копий, использующих принцип петель и паттернов. В этих петлях (зацикленных воспроизведениях отдельных звуков и артикуляций) едва ли решается проблема адекватной передачи гармоник (обертонов), имеющихся в живом исполнении. За счет наслаивающихся друг на друга гармоник при переходе одного звука в другой создается богатство звуковой палитры, но в цифровой записи возможна лишь бледная симуляция этой незыблемой основы акустической музыки с помощью моделирования искусственных обертонов. Впрочем, в некоторых посредственных сэмплерных библиотеках эта проблема вообще никак не решается и обертональное наполнение музыки вообще не учитывается. В наиболее «продвинутых» библиотеках реализуется идея создания симулякра, который оказывается совершеннее оригинала. Для этого записанные сэмплы подвергаются всевозможной обработке, становятся более близкими, яркими, эффектными. Но при прослушивании эта «блестящесть» быстро приедается, в ней всегда присутствует налет мертвенности и неестественности.

Итак, непередаваемая в дигитальности естественность компенсируется симулякром естественности неестественностью, которая стремится выглядеть лучше естественности и в конечном счете поглотить ее, чтобы более не соотноситься ни с каким первоисточником, стать самодостаточной виртуальной реальностью.

Помимо сэмплерных библиотек живых инструментов в компьютерных программах или на специальном «железном» оборудовании (синтезаторах, рабочих станциях, тон-генераторах, DSP-платах) имеется огромное количество электронных сэмплов. И, по сути, они - чистой воды симулякры, поскольку лишены какой бы то ни было референции. Многие электронные звуки создаются в компьютере или на специальном «железе» с нуля, то есть не имеют прототипа ни на каком уровне бытия и реальности, а по сути и никаких миметических качеств и никакого эмоционально-духовного наполнения. Отсюда прямо напрашивается вывод о том, что вся «алеаторическая»

данные: туше, громкость и иные акустические параметры, тембр, темп и тональность с точной привязкой во времени. 
музыка, сделанная исключительно с использованием этих звуков-тембров-сэмплов-лупов (House, Drum and Bass и др.), - также симулякр. Так это или нет - хороший повод для дискуссии, однако очевидно, что в любом случае музыка, основанная на синтезированном звуке, - нечто принципиально иное по отношению к музыке традиционной, акустической. Она иначе слушается, иначе воспринимается, иначе преподносится, и даже создается, сочиняется она совершенно иначе. И это подводит к следующей, созданной дигитальностью проблеме.

\section{Сочинение музыки как симулякр}

Когда-то, когда техника, еще даже и не цифровая, только начала проникать в композиторское творчество, это многих взбудоражило, об этом много говорили, это обсуждали и в частности - автоматизацию, технологизацию композиторского процесса. Появление технологий породило страх, что теперь именно технические устройства и станут композиторами. Впрочем, в действительности ситуация, в которой находятся сегодня создатели музыки, эти самые «живые» композиторы, уже очень сильно отличается от прежней, и технологии действительно играют в ней одну из ключевых ролей. Изменения фундаментальные, порой даже на уровне рецепции. Ведь все чаще музыка делается и редактируется визуально в компьютерных программах, на рабочей станции или портостудии. Глаза композитора становятся не менее востребованными, чем уши.

Но дело, конечно, не столько в этом, сколько в том, что дигитальные технологии обладают весьма широким потенциалом в плане работы со звуком, в то время как традиционные музыкально-выразительные средства практически исчерпали себя и обречены на бесконечное самоповторение. Новый широкий технический потенциал располагается в основном не в области привычной для композиторства - технологии не помогают создать новые мелодии или гармонические ходы (тут едва ли можно придумать что-то новое с технологиями или без них). Вся безграничность возможностей дигитальной техники - в другой области, она касается тембров, стереопанорамы, глубины, компактности, степени плотности/ разреженности звучания, в конечном счете, всего того, что и выливается в понятие саунда. Именно в области экспериментов с саундом и начинают сосредоточиваться основные творческие силы.

Нужно сказать, что развитие музыки уже довольно давно двигалось к этому. Начиная с конца XIX века, мелодия и гармония всё чаще уступают пальму первенства тембральным краскам (например, в импрессионистических звуковых полотнах К. Дебюсси и М. Равеля), сонорным звучностям («Атмосферы» Д. Лигети, «Трен» К. Пендерецкого и т. д., почти все авангардисты отдали дань сонорике). Однако с цифровыми технологиями эта тенденция дошла до своего логического завершения. Музыка, оказываясь в дигитальном пространстве, приобретает еще одно измерение - кибернетически-акустическое, она становится искусством саунда.
Дигитальная технология ведет к тому, что сочинение музыки начинает все больше напоминать симулякр. 0тчасти это связано с тем, что теперь зачастую с большим основанием композиторами можно назвать всю когорту сессионных музыкантов, аранжировщиков, как бы дописывающих в авторский концепт некое коллективное бессознательное. Равно как и звукорежиссеров, собирающих (часто алеаторическую) мозаику, звуковой пазл, корректирующих его, вдыхающих в него жизнь, создающих саунд-концепт, саунд-эстетику. Сочинение музыки становится гипер-интертекстом, куда каждый участник «сейшна» вносит свою лепту. А композитор - лишь автор самой общей идеи, концепта «эйдоса», генеральной интонации, того, что отличает данный трек от другого.

К тому же сам ход процесса создания музыки в дигитальной среде ведет к тому, что значение слова «композитор» как нельзя более приближается к своей этимологии (лат. compositor - составитель). Это ведь иллюзия творчества - использовать эффекты, паттерны, сэмплы, лупы производителей «железного» музыкального оборудования и программного софта и без стеснения ставить свою фамилию под очередным как-бы-музыкальным опусом! Производители софта всячески потакают моде в среде композиторов комбинировать музыку из готовых мелодических, гармонических, ритмических, текстурных «нарезок». Во многих сэмплерных библиотеках представлены уже готовые фрагменты, часто с обозначениями темпа, тональности (например, библиотеки сэмплов в wave-формате «Vergeance»).

Неудивительно в итоге, что не только роль композитора, но и сам процесс его работы все больше и больше напоминает симуляцию - созидание, внутренний смысл, первообраз которого давно утрачен. Связь создателя музыки с естественным пространством звука и с естественным пространством внутренних смыслов - как бы два разных, не очень взаимосвязанных и совершенно необязательно пересекающихся явления. Однако на практике сегодня все чаще выходит так, что обе - случайно ли это или нет - разрываются одновременно.

Между тем собственно композиторская часть работы - создание музыки -это лишь первый этап и первая ступень дигитальной лестницы. Над ней возвышается следующая ступень, вклинивающаяся между арт-объектом и реципиентами запись и обработка аудиотреков.

\section{Запись фонограммы и модификация дигитального звука как гиперреально-симулятивные процессы}

За изменениями в композиторском процессе сегодня стоит много других изменений звука, которые совершаются в дигитальном пространстве уже на стадии пост-композиторской, хотя и все реже эту стадию «пост» можно как-то вычленить, отделить от собственно процесса сочинения. Ведь сегодня появляется много музыки, бытие которой исключительно дигитально, она никогда не исполнялась (в традиционном смысле), но лишь записывалась в студии «кусками» - фрагментами, не звучала 
по-настоящему, но существует исключительно в виде последовательной смены цифр. Она гиперзависима от техники, техника диктует ей многое.

Впрочем, для любой музыки, вне зависимости от ее способности бытовать вне цифрового контекста, наступает сегодня момент записи дигитальной фонограммы - особый процесс: это не сочинение музыки, это не исполнение, это даже не музицирование. Здесь никто не может назвать себя автором, хотя каждый вносит свою лепту. Здесь нечего интерпретировать, хотя роль интерпретатора отчасти берут на себя звукорежиссер, мастеринг-инженер. Именно они отвечают за конечный саунд, за «эстетическую ауру» музыки. Это гиперинтертекст, куда все сессионные музыканты «дописывают» что-то от себя.

Музыка, которая получается на выходе таких экспериментов, столь же далека от музыки в традиционном понимании, как и 5D боевик от шекспировского театра, но это не значит, что она, музыка, становится проще, примитивнее. Для создания качественного музыкального продукта необходимо потратить гораздо больше усилий, чем в прежние времена, нужно больше способностей, больше знаний, больше людей, несоизмеримо больше денег.

Однако при этом на стадии записи и обработки в дигитально-ориентированной и дигитально-модифицированной музыке происходит смещение ценностных установок: главным становится качество звука, умение обработать музыку, скрывая возможные недостатки исполнения. Подчас это «улучшение» делает неестественными голосовые или инструментальные тембры. Но эта неестественность принимается за правило и становится естественной в рамках цифровой музыки.

Ту же тенденцию легко проследить в сегодняшних аудиозаписях звезд эстрады - в них нет ни одной ошибки, они просто невозможны. Исполнение ими музыки гиперреально, так как каждое ее воспроизведение совпадает с самим собой. Коммерческая музыка искусственно идеальна: электронные аналоги живых инструментов и голосов совершеннее настоящих, они не скрипят, не пищат, не фальшивят, они безупречны. Певец стремится быть сверхчеловеком, ему нужен не только идеальный голос, но и идеальная внешность, идеальный клип, идеальный продюсер, идеальная запись, и только тогда он состоится как товар, тогда он может котироваться.

Искусство звукорежиссуры предусматривает целый набор «косметических процедур» для голоса (типа обработки де-эссером и ревербератором), в «криминальных» случаях голос накачивают метафорическим латексом и ботоксом (исправляют фальшь тюнером, «осветляют» пение эксайтером). В результате «тело голоса» в попмузыке становится безупречно-идеальным и абсолютно безжизненным.

Собственно говоря - это лишь органичная часть процесса, ведь современная поп-музыка вообще становится гиперреальным герметичным художественным пространством. Гиперреальным - так как напрямую корреспондирует с масс медиа и виртуальностью и способна на бесконечное тождественное воспроизведение самой себя. Это бесконечное самовоспроизведение начинается со способа делания фонограммы, когда, например, такты барабанных лупов-партий копируются-клонируются, вставляются в следующий такт (или, например, копирование припева после каждого куплета в вокальной партии), а заканчивается тиражированием, распространением на электронных носителях клонов музыкальной продукции. Гиперреальность, получаемая в результате клонирования, есть среда симулякров.

Однако и за пределами поп-вселенной эволюция звукотехники оказывает значительное влияние на музыку. Используемые способы аранжировки, выстраивание фактуры в современной музыке во многом обусловлены переходом к многоканальной записи, возможностям стереофонии, совершенствованием технологии звукосинтеза, внедрением стандарта General MIDI и др. Записанный и обработанный звук оказывается в виртуальном аудиопространстве.

Созданное звукоинженерами аудиопространство не всегда соответствует тем акустическим условиям, к которым мы привыкли в реальности. Собственно, большая часть акустической картины в виртуальной музыке искусственно моделируется: компрессия, эквализация, реверберация (как эмуляция отражений несуществующих пространств), расширение стереобазы (добавление звуку пространственной информации - симуляция пространства) - всё это технологические ухищрения, переводящие музыку в гиперреальную плоскость. В последнее время стало модно выпускать программные продукты, связанные с обработкой и сэмплированием звука, которые имитируют поведение и звучание дорогих цифровых и аналоговых устройств. Как правило, программные продукты уступают в качестве «оригиналам», являются некой деградирующей копией, бесконечно приближающимся к первоисточнику симулякру, который никогда не сможет стать неотличимым от первоисточника, поскольку использует иные принципы кодирования аудиоинформации.

Звуковая обработка - это попытка компенсировать «дефектность» изначальной записи (и - шире - живого звука вообще). Уже заявленная проблема - невозможность полностью адекватно передать естественную акустическую картину в среде единиц и нулей порождает множество аудио-недостатков в процессе записи и множество путей борьбы с ними, которые в свою очередь принадлежат уже целиком пространству симуляции. Так, расстановка множества микрофонов вокруг и вдали от аудиоисточника призвана сгладить этот недостаток, но на самом деле предлагает лишь гиперсимулякр «присутствия» инструмента, маскируя невозможность аутентичной записи.

Искажения вносятся также в момент преобразования аналогового сигнала в цифровой. Шумы цифровых приборов неизбежны - и их затушевывают при сведении, внося тем самым очередной слой искусственных искажений, который непременно будет присутствовать в каждой записи.

После записи начинается сведение, которое является попыткой сгладить недостатки цифры и возвратить 
инструменту его «реальное» (скорее даже, гиперреальное) звучание, при помощи комплекса технологических процедур. Модным становится такое преобразование записанного звука, которое делало бы его лучше (с точки зрения кибернетической логики), чем он был до оцифровки: «ближе», эффектнее, чище, стерильнее. Ему добавляют пространственной информации, глубины, изменяют частотные характеристики и т. д. При записи и сведении/мастеринге музыкальной продукции «в цифре» симулируются динамика и пространство. Ведь в «реальности» обычно все музыкальные инструменты по громкости звучат не так, как в записи и тем более никак не компрессируются и не эквализуются. Динамический диапазон в цифре корректируется как для создания более выгодных эстетических характеристик звука (плотность, ясность и др.), так и для технического соответствия требованиям массмедиа (на телевидении любой звук подгоняется под определенные динамические и частотные характеристики). Снятый микрофонами звук значительно отличается от живого, естественного, так фортепиано записывается обычно четырьмя-пятью, а то и более, микрофонами, для наиболее выгодного яркоброского звучания в цифре.

В записи часто все музыкальные инструменты располагаются по панораме не так, как в жизни. К тому же они обрабатываются ревербераторами для создания как бы живого жизненного пространства, в действительности это его компьютерная или «железная» симуляция. Часто в реальности не существует помещения с такими пространственными характеристиками, которые симулируются ревербераторами.

В конечном итоге весь процесс сведения и обработки направлен на одну цель - замаскировать невозможность фиксации реального музыкального образа, создания его неискаженной цифровой копии. Фактически эта маскировка приводит к созданию образа далекого от подлинника по сути, но в то же время - даже гиперреального.

Посредством психоакустических процессоров, компрессоров и эквалайзеров возникает эффект твердоплотно-близкой музыки. Звук становится гипернавязчивым, не оставляет места никакой эстетической дистанции, не иначе как вдалбливается непосредственно в сознание и подсознание. Именно этого пытаются добиться в процессе записи фонограммы и обработки - в конечном итоге создать такой идеальный симулякр, который скрывал бы отсутствие чего-то ключевого, но при этом был бы идеальнее идеала и реальнее самой реальности.

\section{Прагматический уровень симулякризации дигитальной музыки. \\ Воспроизведение музыки как симулякр}

На самом деле гиперреальность дигитальной записи - всего лишь очередная ступень. В дигитальной культуре музыке предстоит стать еще более реальной гипер-гиперреальной на следующей ступени дигитальной лестницы - в момент музыкального воспроизведения. Здесь сегодня тоже включаются в дело особые логика и принципы. Они очень тесно смыкаются с постмодернистским пространством гиперреальной симуляции. 06 этом пишет Ж. Бодрийар. Он констатирует, что все современное искусство погружено в сферу гипертехничности, гиперэффективности, гипернаглядности. Не остается никаких белых пятен, никаких пустот, никаких эллиптических намеков, никакой тишины. Искусство, по замечанию Ж. Бодрийара, идет по пути высокого разрешения, по пути бессмысленного совершенствования четкости образа. Такой сверхчеткий образ перестает быть собственно образом. Он превращается в реальность, осуществляясь в реальном времени, в то время как абсолютное разрешение, реалистическое совершенство образа лишает образ способности порождать иллюзии. Апогей обезображивания образа связан с его дигитализацией и виртуализацией, здесь образ перестает быть образом. Ведь смысл образа состоит в абстрагировании от трехмерного мира и переходе в двухмерный мир. Иллюзия, в философии Ж. Бодрийара, обретает силу благодаря тому, что образ вычитает у реальной трехмерности одно измерение. Виртуальность, напротив, заставляет нас войти в образ, воссоздавая поддельную реальность в трех измерениях и даже добавляя к реальности еще одно - четвертое измерение, превращая ее тем самым в гиперреальность. За счет этого, по мнению Ж. Бодрийара, уничтожается иллюзия. Виртуальность стремится к созданию совершенной иллюзии. Но при этом она прямо противоположна созидательной иллюзии образа. Виртуальность создает иллюзию «рекреационную», рекреативную, реалистическую, мимическую, голографическую. Иллюзия гиперсходства, иллюзии совершенного реалистического стереотипа убивает в иллюзии ее глубинное измерение.

Именно это рассуждение Ж. Бодрийара имеет прямое отношение к такому дигитальному тренду, как гиперреальная виртуализация звука на стадии воспроизведения (культ стереофонии, переходящей в квадрофонию, и т. д.). То есть все технологии воспроизведения, направленные на максимальное погружение слушателя в виртуальное пространство звука, его окутывание им. Стереофония, пишет Ж. Бодрийар, в своей технологичности кладет конец обворожительности и восприятию музыки [1]. Появление квадрофонической техники французский эссеист считает идеальным музыкальным преступлением. Это совершенное воспроизведение звука нивелирует собственно «музыкальную иллюзию», которая, как и образ, принадлежит параллельной вселенной. Звук возводится в ранг предмета. Усовершенствованный, он оказывается непосредственно данной вещью, а не тем, что воспринимается издалека [2, с. 90].

Ж. Бодрийар считает технологическим безумием попытки воспроизвести музыку Баха, Монтеверди, Моцарта «квадро-мультифонически», ведь она никогда не существовала в таком виртуально-дигитальном «пространстве», которую так никто никогда не слушал и не сочинял, чтобы так слушать. Впрочем, говорит Ж. Бодрийар, ее и не «слушают». Дистанция, позволяющая слушать музыку (скажем, на концерте), сведена на нет, вы обложены со 
всех сторон, нет больше музыкального пространства. Всё - одна тотальная симуляция эмбиента, отнимающая у слушателя тот минимум аналитического восприятия, без которого музыка лишается своих чар.

Ж. Бодрийар пишет, что четвертое измерение, добавленное к музыке, - это орудие кастрации реципиента, лишающее способности получать музыкальное наслаждение. Здесь начинает завораживать иное - техническое совершенство, hi-fi, «высокая верность». Неизвестно, правда, чему верна эта верность, ведь где начинается и где кончается реальность и умопомрачение ее перфекционистского воспроизведения? Техника, совершенствуя средства синтеза, усугубляет критерии анализа и разрешающей способности. Так что полная верность, исчерпывающая точность применительно к реальному становятся невозможны. Реальное превращается в умопомрачительный фантазм точности, теряющийся в бесконечно малом. «Нормальное» трехмерное пространство по сравнению с двухмерным - это деградация, обеднение вследствие избыточности средств. По мнению Ж. Бодрийара, квадрофония, гиперстерео, hi-fi - это явная деградация [3, с. $71-72]$.

Отсутствие романтизирующей дистанции эффекта сцены заходит сегодня гораздо дальше: сценой оказывается все вокруг, и не только потому что сценическое действо окружает человека как звуковая картина, но и потому, что сам он становится этого действа непосредственным участником - нормой для дигитальной вселенной становится интерактивность музыкального восприятия.

\section{Интерактивность музыкального восприятия}

Одно из существенных свойств дигитально-виртуальной музыки - интерактивность. Пользователь персонального компьютера, оснащенного колонками или наушниками, теперь может самостоятельно регулировать громкость треков, начинать прослушивание с произвольно выбранного места, создавать списки воспроизведения. Во многих софтовых музыкальных проигрывателях имеется возможность частотной регуляции, подбора визуального ряда. Специализированные программы работы со звуком предлагают более широкий спектр возможностей управления звуком: от высотной коррекции до разного рода искажений. Таким образом, звуковые объекты реально трансформируются в соответствии с заданными параметрами. Еще Г. Гульд писал, что новые технологии формируют новый тип слушателя, который реально участвует в музыкальном творчестве. Такой слушатель способен вносить свой вклад в интерпретацию, изменяя параметры воспроизведения звука [4, с. 110-111].

В техническом плане мечта Г. Гульда вполне осуществилась. Достаточно заглянуть в интернет-пространство, чтобы это в полной мере ощутить, - там сегодня вся музыка, по сути, превратилась в гиперинтертекст.

Один и тот же музыкальный артефакт может: фигурировать под разными названиями (затрудняющими его «различание»); иметь разную длину (кто-то может обрезать начало или конец) и разное звучание (кто-то загружал аудиофайл в социальную сеть с лицензионного CD-диска, кто-то в сжатом формате Мр3 или оцифровывал с кассеты). Появляются виртуальные миксы-нарезки из кусков-фрагментов различной музыки, склеенной произвольно.

Обычно подобное «креативное» обращение с классикой столь сильно отдаляется от первоначального замысла композитора, что попадает в разряд симулякра, то есть деградирующей копии, в которой уже не угадывается изначальный духовно-трансцендентальный эйдос, имманентный оригинал: он предстает в «копии» в значительно искаженном виде. Это не значит, что любая смелая трактовка музыки академического жанра автоматически превращается в симулякр, но лишь та, которая стремится к обструкции или лишена эстетических качеств, художественно неубедительна. Утопическая мечта Г. Гульда о том, что слушатель будет «склеивать» наиболее удачные фрагменты интерпретаций различных музыкантов в единое целое, создавая «собственный» вариант шедевра, на практике привела к появлению в Интернете множества посредственных «доработок» классики, среди которых подчас трудно найти более или менее аутентичный вариант исполнения и достойной записи.

\section{Ультрамузыка, новая синкретичность}

Дефицит подлинного в дигитальности компенсируется бесконечным расширением художественного предмета, его выхождением за собственные пределы. Цифровая музыка теряет свою автономию и встраивается в контекст «новой синкретичности». Музыка погружается в аудиовизуальное пространство, сливается с видеоклипом, с образом артиста вообще. Н.Б. Маньковская пишет, что техника мультиплицирования акустических и визуальных слоев-двойников, создание компьютерных музыкальных видеодисков расширяют возможности творческого самовыражения [5, с. 320-321]. Виртуальное бытие музыки тесно коррелирует с видеообразами, дигитальное искусство ориентировано на гиперцепцию. Ее теперь невозможно отделить от внемузыкальных элементов, которые вкупе с ней и по отношению к ней могут рассматриваться как «ультрамузыка». Подобная ультрамузыка ориентирована на гаптическое переживание. Ультрамузыка как феномен аудиодигитальности логично вытекает из концепта симулякра. За счет пестроты и эффектности объектов восприятия как бы восполняется художественная бедность многих новейших ультрамузыкальных объектов. Им нечего предложить, кроме операционально, технически совершенного мультирецептивного продукта, чьи трансцендентально-эстетические характеристики оставляют желать лучшего.

В этой своей новой синкретичности дигитальное искусство представляет собой сложное сочетание аскезы и растраты. В творчестве вообще всегда взаимодействуют два принципа: принцип аскезы и принцип растраты. В разные эпохи, в разных стилях они оказываются в раз- 
ной степени выраженными. Их соотнесенность в произведении (арт-практике, арт-продукте) обусловливается разными факторами: художественно-эстетическими задачами, своеобразием манеры письма.

Аскеза - это принцип экономии творческих сил, сбережения выразительных ресурсов, тщательно-скупая расстановка элементов художественной системы, воздержание от неоправданных сопоставлений, от яркости и броскости, от экспликации эмоционально-волевого начала, от просодической пестроты, от мозаичности. Аскеза предполагает умерщвление несущественного, отказ от всего излишнего и концентрацию на главном (то есть на том, что позиционируется как главное) - рельефе и выпуклости основного, редукция всего множества к единому. Аскеза связана с идеальной (по крайней мере, стремлением к идеалу) техничностью, технологичностью артефакта-феномена, укрытием соблазна, бегством от него, стыдливостью в отношении соблазна.

Растрата, напротив, характеризуется щедростью и богатством материала, некоторой небрежностью в обращении с ним, часто связана с рыхлостью структуры. Она культивирует визуальность роскоши, поверхность и непосредственность, связана с эротичностью и бесстыдной обнаженностью чувств, культом соблазна. Растрата связана с эстетикой потлача, мозаичностью материала.

В аскезе происходит восполнение растраты путем концентрации на глубине воплощения конкретного. Растрата оказывается внутренним стержнем аскезы, растрата перетасовывает лишь идеально сочетающиеся друг с другом элементы, растрата перестает быть расточительной, но оказывается аккумулирующей. Растрата как доминантный принцип также вбирает в себя аскезу. Она действует внутри узурпированного ее эстетической аскезой круга, позволяя насладиться лишь уже отфильтрованными аскезой качествами и параметрами. Аскеза и растрата обеспечивают позитивное становление художественной системы, ее нестабильную стабильность (метастабильность) и распадающуюся / собирающуюся целостность.

Но в то же время аскеза музыкальной дигитальности заключается в совершенной упругости и дышащей скомпрессированности, посаженности треков, ограниченности и выверенности аранжировок, идеальной слаженности в записи (в том числе сведенного оттюненного вокала), в тщательной подборке элементов для видеоряда, аскетично жилистых, накачанных и недоступных тел (искушающих, но в то же время сохраняющих арт-дистанцию). Ограничение звучания лишь до идеальной нормы под девизом «ничего лишнего, только самое необходимое», аскеза в виде холодно-совершенной спортивности, привлекательности звезд. Все здесь рассчитано на запечатление хрупкости и зыбкости момента совершенства и его виртуальную доработку благодаря возможностям преобразования и преображения в дигитализированном пространстве. Стоит лишь изменить грим, скосить ракурс, применить не тот эффект при монтаже, и идеальность тотчас разрушится. Она остается вечной лишь в результате оцифровки, которая знаменует победу над несовершенством нецифрового мира. Это победа вечной хрупкости.

В дигитализированном арте во всём чары обольщения без соблазна: наслаждение красотой предполагает «музейное созерцание», невмешательство. Дигитальное искусство это победа качества представления, обольщение моделируемым идеальным, в котором становятся безразличны и предельно аскетичны собственно содержание и форма. Они отступают на дальний план и служат лишь функционированию совершенствующегося совершенства. Прельщает глубина, близость и воздействие самих частот, гиперидеальной точности пикселизации, содержание оказывается лишь констатацией, выражение тестируется на соответствие дигитальным эталонам.

Есть в этом кибернетическом романтизме нечто завораживающее. Контрапункты как констатация симулякра присутствия, голос как символ присутствия человеческого (метаморфизированного в некоего гуманоида - с идеальной дикцией, динамикой и интонацией, ритмом). Подстраиваться под дигитальную техноэстетику - значит становиться аскетом, значит воздерживаться и ограничиваться, проецировать растрату в программируемую глубину лимитируемых параметров. Создавать такой мультисимулякр гиперцептивной иллюзии, который не оставлял бы ничего за своими пределами, погружал бы полностью, без остатка в матрицу идеальности с ее сложнейшей примитивностью.

В этой «новой синкретичности» виртуальности можно усмотреть секуляризованный, десакрализованный, деконструированный вариант идеи «Мистерии» А. Скрябина. Все искусства слиты воедино и доступны восприятию всего человечества благодаря Всемирной сети. Как «Мистерия» русского гения явилась предчувствием экзистенциальных потрясений и коренных перемен в жизни человечества, и больше того - знаменем апокалипсиса и сценарием его эстетизированного воплощения, так и на фоне становления дигитально-виртуального универсума стали звучать голоса об эсхатологичности нашего времени.

\section{Список литературы}

1. Бодрийар Ж. Симулякр и симуляция [Электронный ресурс]. - Режим доступа: http://lit.lib.ru/k/kachalow_a/ simulacres_et_simulation.shtml

2. Бодрийар Ж. Пароли. От фрагмента к фрагменту / пер. с франц. Н. Суслова. - Екатеринбург: У-Фактория, 2006.

3. Бодрийар. Ж. Соблазн. - М.: Ad Marginem, 2000.

4. Гульд Г. Перспективы звукозаписи. Избранное. В 2 кн. Кн. 2. - М.: Издательский дом «Классика-XXI», 2006.

5. Маньковская Н.Б. Эстетика постмодернизма. - СПб.: Алетейя, 2000. 